\title{
News from the Canadian Society of Animal Science
}

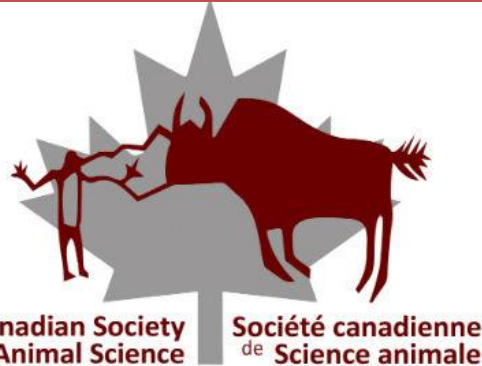

www.csas.net

Visit:

https://www.asas.org/CSAS/csas-membership

and signup to become a member
CSAS: where science nourishes productivity

A society for persons involved in every aspect of the Animal Sciences: Professionals, Industry Leaders, Farmers, Students, Business Owners, etc.

MEMBERSHIP BENEFITS

$\checkmark$ Foster animal agriculture solutions for a hungry world.

$\checkmark$ Ensure humane care of livestock.

$\checkmark$ Get recognition through CSAS sponsored awards.

$\checkmark$ CSAS sponsored travel awards for students to attend annual meetings.

$\checkmark$ Discounted cost of registration for annual meetings.

$\checkmark$ Reduced cost to subscribe to Canadian Journal of Animal Science (CJAS).

$\checkmark$ Discounted page charges for accepted manuscripts in CJAS.

$\checkmark$ Be the first to know when a new issue of CJAS is available.

$\checkmark$ Propose topics for Animal Frontiers Magazine/act as guest editor.

$\checkmark$ Quality networking among members.

$\checkmark$ Quality networking among professional animal science societies globally.

$\checkmark$ On-line access to the membership list.

$\checkmark$ Participation in membership discussions on CSAS events/activities/issues

\section{Canadian Journal of Animal Science Welcomes new Editor-in-Chief}

Dr. Filippo Miglior assumes the position of editor-in-chief Canadian Journal of Animal Science (CJAS) starting January $1^{\text {st }}, 2019$. Filippo brings to the journal a wealth of experience both from the industry and academia. Filippo, originally from Milan, Italy, moved to Guelph in 1989, and in 1994 obtained his PhD in Animal Breeding. He moved back to Italy where he held the positions of R\&D Manager at Italian Holstein Association, and at Livestock Farmers Association in Rome. In 2000, Filippo returned to Canada as Research Scientist with AAFC, co-located at Canadian Dairy network as R\&D Coordinator.

In 2013, Filippo accepted the position at CDN as Chief, Research and Strategic Development. In January 2019, he has started at Ontario Genomics as Chief Scientific Officer and Vice President of Sector Innovation and Programs. He is also Adjunct Faculty at University of Guelph since 2004 and Past President of CSAS. Filippo is the recipient of several prestigious awards (2018 ASAS Rockefeller Prentice Award in Animal Breeding and Genetics; 2016 CSAS Technical Innovation in Enhancing Production of Safe Affordable Food; 2013 ADSA JL Lush award in Animal Breeding). Filippo is author of 2 book chapters, 114 scientific journal articles, and over 600 articles/conference proceedings.

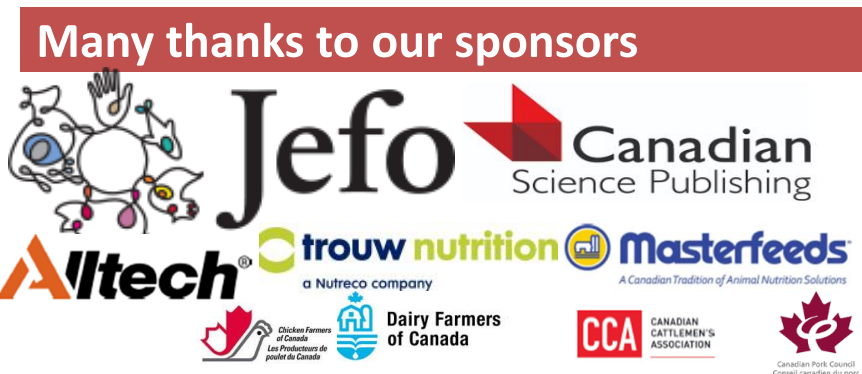

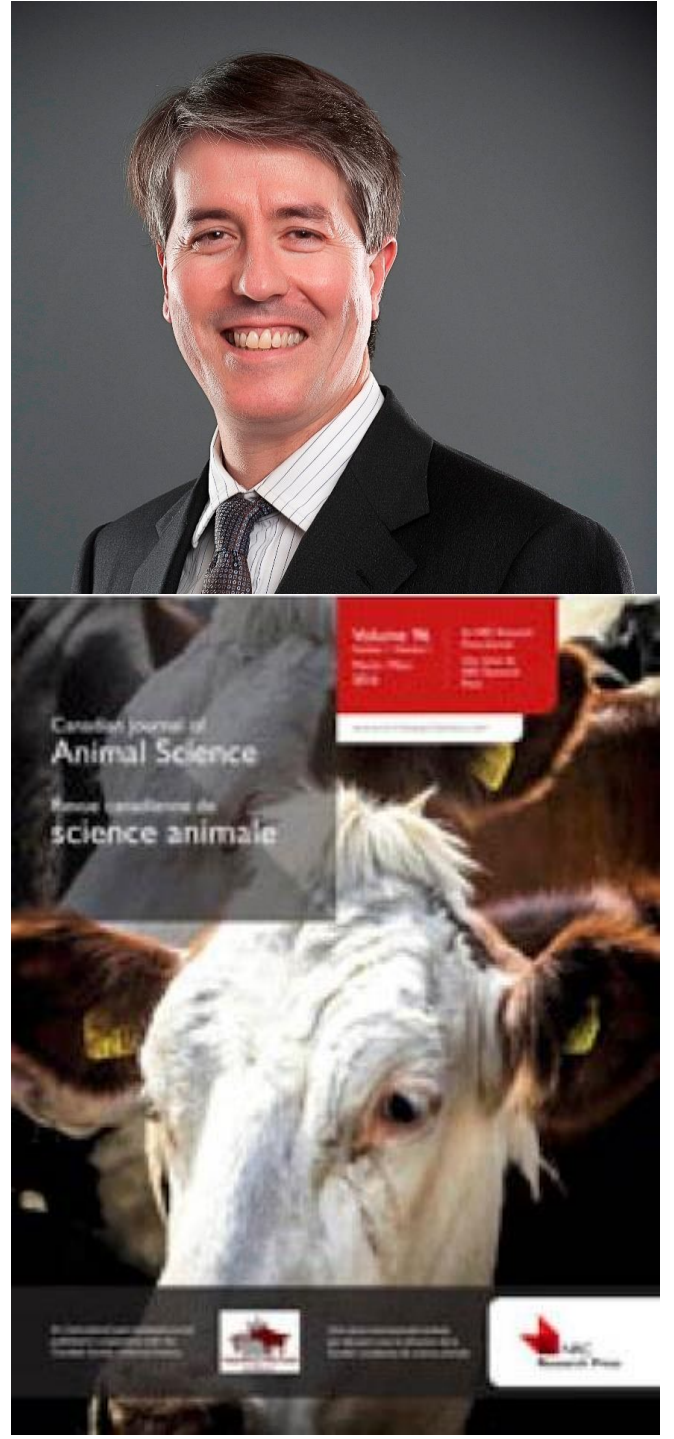

For publication of your next article 